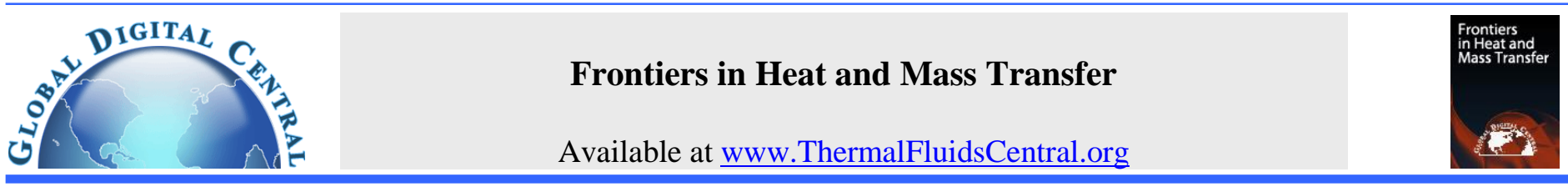

\title{
STUDY ON THERMAL AND HYDRAULIC PERFORMANCE OF THE FINNED FLAT-TUBE HEAT EXCHANGER WITH SINGLE ROW AND ITS OPTIMIZATION
}

\author{
Weiwei Zhang, Linghong Tang* \\ School of Mechanical Engineering, Xi'an Shiyou University, Xi'an 710065, Shaanxi, China
}

\begin{abstract}
Air-side thermal and hydraulic performance of the finned flat-tube heat exchanger with single row is experimentally investigated. The correlations of the thermal and hydraulic performance are developed based on the experimental data. The effects of various fin geometrical parameters on the thermal and hydraulic performance are investigated by a numerical method, and the influence of various parameters is analyzed in detail. Results show that heat transfer performance and pressure drop decrease with the increasing fin pitch, and heat transfer performance increases with the increase of fin length and fin height accompanying with the increase of pressure drop. The design parameters of fin are optimized by the Taguchi method. Twenty-five kinds of models are made by compounding levels on each factor, and the thermal and hydraulic performance of each model is analyzed. The optimal condition is acquired by analytical results.
\end{abstract}

Keywords: Finned flat-tube heat exchanger, Thermal and hydraulic performance, Optimization, Taguchi method.

\section{INTRODUCTION}

For combined cycles of a power plant, the heat dissipation scheme to the environment consists of a steam surface condenser and/or a wet or dry cooling system. The heat of condensing steam is removed in a shell and tube heat exchanger by a continuous loop circulating water system in a wet cooling system, while dry cooling systems transfer heat by convection and radiation instead of evaporation as in wet cooling (Taweny et al., 2005). Compared with water cooling, the water resource can be availably saved by dry air cooling. A $200 \mathrm{MW}$ air-cooled heat exchanger can save 5,000 t/d or 1800,000 t/y water compared with the water-cooled one, which is attractive to solve the electric power generation problem in water deficient but coal rich regions, such as Shaanxi, Shanxi and Inner Mongolia in the north region of China (Wang et al., 2008). Finned flat-tube heat exchangers are extensively employed as air-coolers, and the dominant thermal resistance is usually on the air-side in these applications. Therefore, the use of finned surfaces on the air-side is very common to effectively improve the overall thermal performance of these heat exchangers.

During the past few years, there have been many investigations on the air-side performance for wavy fin (Xu et al., 2015; Duan et al., 2016; Sadeghianjahromi et al., 2018), offset strip fin (Ozturk et al., 2019), louver fin (Karthik et al., 2015a; Karthik et al., 2015b; Erbay et al., 2017), and vortex generator fin (Dezan et al., 2015; Sahel et al., 2017). The results of these investigations showed that the enhanced fin could significantly increase the thermal performance than plain fin. But, the environmental condition is relatively harsh, dusty and windy in the north region of China, and what's more, the fin layout in the air-side is rather compact and the fin spacing is small. Therefore, the dust can easily accumulate on the fin surface, resulting in a decrease in heat transfer coefficient of air-cooler, an increase in steam turbine back pressure and a decrease in turbine unit operating efficiency (Yang et al., 2007). In order to maintain the thermal performance of air-cooler, the air-side of heat exchangers need to be cleaned frequently, which wastes water resources. Since the plain fin is easily cleaned, the thermal performance of plain finned tube heat exchangers is reliable in a longtime running. Thus, the plain finned heat exchanger is usually used in a dusty air. According to the studies above, the previous researches mainly focused on investigating the effects of fin types and different parameters on the thermal and hydraulic performance of finned flattube heat exchangers, but there is not much detailed information about the optimal design parameters for the finned flat-tube heat exchangers in the literature.

In this study, the influence of various design parameters on the thermal and hydraulic performance of a plain finned flat-tube heat exchanger with single row is analyzed by a numerical method. The Taguchi method (Roy, 2010; Zeng et al., 2010; Tang et al., 2016; Tang et al., 2019a) is introduced into the present study for optimization and the database is also obtained by a numerical method. The results also provide us with quantitative estimation of the various parameters affecting performance, and the main factors for optimal design are selected. The optimal design value of each parameter is presented, and the reproducibility of the results is also discussed. The results may provide a practical guidance on the design of the plain finned flat-tube heat exchanger.

\section{EXPERIMENTAL RESULTS AND DISCUSSION}

\subsection{Experimental System}

The experiments are conducted in an open wind tunnel. The system consists of two loops: air loop and steam loop. The air loop is provided to blow air across the finned bundles of test core, and the steam loop is designed to supply slightly superheated stream through the tubes of test core. The extended (finned) surfaces are prepared for the test core, which are placed in the test section. The steam-air system is employed

\footnotetext{
${ }^{*}$ Corresponding Author. E-mail: lhtang97@163.com
} 
for accomplishment of steam-to-air heat exchange, as schematically shown in Figure 1.

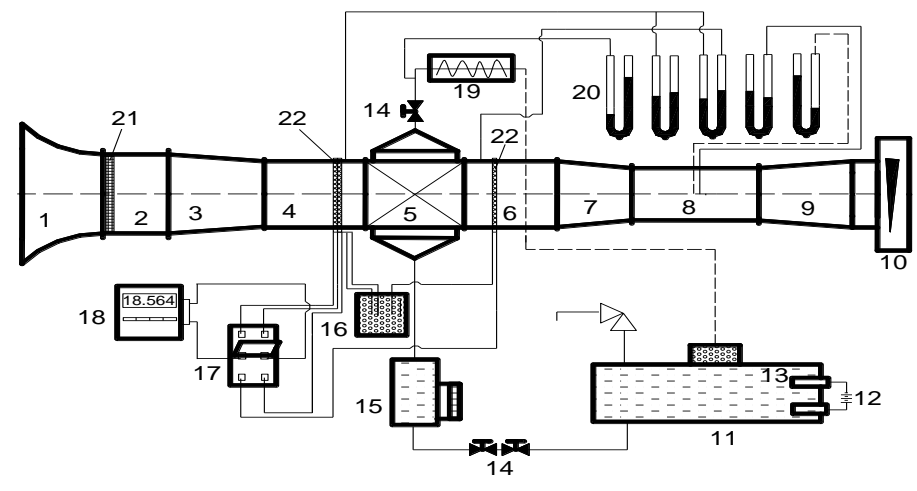

1-Entrance; 2-Transition section; 3-Contraction section; 4-Straightening section; 5-Test section; 6- Straightening section; 7-Contraction section; 8-Flow metering duct; 9-Expansion section; 10-Blower; 11-Boiler; 12Power source; 13-Electric heating rod; 14-Valve; 15-Volume flowmeter; 16-Ice bath; 17-Transfer switch; 18-Digital voltmeter; 19-Overheater; 20-U tube manometer; 21-Grid; 22-Thermocouples grid

Fig. 1 Schematic diagram of the experimental system.

Air is induced to the wind tunnel by a centrifugal blower. Air flows in turn through the entrance, transition section, contraction section and straightening section before reaching the test core. The regulation and uniform distribution of air are achieved along these three sections between the entrance and test core. The inlet air temperature and the temperature difference between inlet and outlet through the test core are measured by two sets of multi-point T-type copper-constantan thermocouple grids. Each set contains sixteen calibrated thermocouples within the accuracy of $0.1 \mathrm{~K}$, and the junctions of thermocouples are connected in series to give a single reading. Steam is generated in an electrically heated boiler, of which the power can be adjusted by six transformers. After flowing through the overheater, the steam is superheated to provide the desired $1 \sim 3 \mathrm{~K}$ of superheat. The superheated steam temperature is directly read with an ethanol thermometer, which is inserted in the hole that designed in the steam inlet header.

The wall static pressures before and after the test heat exchanger are measured by a U-tube water column manometer, and the superheated steam pressure is read by a U-tube mercury column manometer. The air velocity is measured by a Pitot-tube meter, which is located in the flow metering duct far downstream of the test core. The Pitot-tube meter is connected to the inclined draft gauges (at small flow rate) or U-tube water column manometer (at high flow rate).

Before recording the data in the experiments, much attention is paid on the thermal equilibrium to ensure the steady state of heat exchange. The steam gauge pressure is maintained around $200 \mathrm{mmHg}$ (mercury column), and the potential of thermal couple varies around $0.01 \mathrm{mV}$. In the data-acquisition procedure, each measured value is read five times in ten minutes, and the arithmetic mean of the recorded data is used for checking the heat balance between the energy gain of air and the energy reduction of the condensing steam. In all tests, the thermal equilibrium between air-side and steam side is within $5 \%$.

The test core is a plain finned flat-tube heat exchanger with single row. Tubes are made of carbon steel, and fins are made of aluminum. The fins are connected to the flat tubes by brazing, so the contact thermal resistance could be neglected. The detailed geometrical parameters of the heat exchanger are tabulated in Table 1 and schematically shown in Figure 2.
Table 1 Geometric dimensions of the finned flat-tube heat exchanger.

\begin{tabular}{|l|l|l|}
\hline Parameters & Symbol/unit & Values \\
\hline Flat tube diameter & $d / \mathrm{m}$ & 0.019 \\
\hline Flat tube thickness & $\delta_{\mathrm{t}} / \mathrm{m}$ & 0.0015 \\
\hline Fin thickness & $\delta_{\mathrm{f}} / \mathrm{m}$ & 0.0003 \\
\hline Fin length & $F_{\mathrm{L}} / \mathrm{m}$ & 0.2 \\
\hline Fin height & $F_{\mathrm{H}} / \mathrm{m}$ & 0.019 \\
\hline Fin pitch & $F_{\mathrm{p}} / \mathrm{m}$ & 0.0024 \\
\hline Flat tube pitch & $S / \mathrm{m}$ & 0.058 \\
\hline Width of front area & $W / \mathrm{m}$ & 0.464 \\
\hline Length of front area & $L / \mathrm{m}$ & 1.0 \\
\hline
\end{tabular}

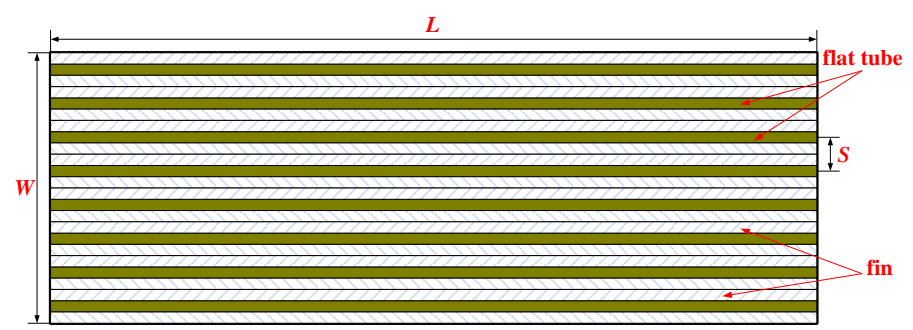

(a) Cross-section

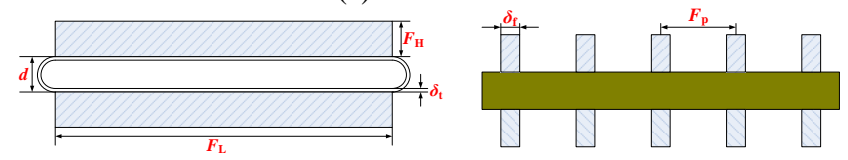

(b) Part of finned flat tube

Fig. 2 Schematic view of the finned flat-tube heat exchanger.

\subsection{Data Reduction}

The saturated steam gauge pressure in the tubes is around $200 \mathrm{mmHg}$. The steam-side heat transfer rate $Q_{\text {steam }}$ is given as

$Q_{\text {steam }}=m_{\text {steam }} r_{\text {steam }}$

where $m_{\text {steam }}$ is the vapor mass flowrate, and $r_{\text {steam }}$ is the latent heat of steam at the corresponding pressure. The air-side heat transfer rate $Q_{\text {air }}$ is given as

$Q_{\text {air }}=m_{\text {air }} c_{\text {pair }} \Delta t_{\text {air }}$

where $m_{\text {air }}$ is the air mass flowrate.

The total heat transfer rate is defined as the average of the air-side and the steam-side heat transfer rates

$Q_{\text {ave }}=\left(Q_{\text {steam }}+Q_{\text {air }}\right) / 2$

The total heat transfer coefficient, $k A$ product, is calculated from the following relationship

$k A=Q_{\text {ave }} / \Delta t_{\mathrm{m}}$

where $\Delta t_{\mathrm{m}}$ is the logarithmic-mean temperature difference and defined by

$\Delta t_{\mathrm{m}}=\left(\left(t_{\mathrm{s}}-t_{\text {in }}\right)-\left(t_{\mathrm{s}}-t_{\text {out }}\right)\right) / \ln \left(\left(t_{\mathrm{s}}-t_{\text {in }}\right) / t_{\mathrm{s}}-t_{\text {out }}\right)$

where $t_{\text {in }}$ is the inlet temperature of air, $t_{\mathrm{out}}$ is the outlet temperature, and $t_{\mathrm{s}}$ is the saturated temperature of steam at the corresponding pressure.

The overall heat transfer resistance can be defined as

$\frac{1}{k}=\frac{1}{\eta_{\mathrm{o}} h_{\mathrm{o}}}+\frac{\delta_{\mathrm{t}} A_{\mathrm{o}}}{\lambda_{\mathrm{t}} A_{\mathrm{i}}}+\frac{A_{\mathrm{o}}}{h_{\mathrm{i}} A_{\mathrm{i}}}$

The steam-side heat transfer coefficient, $h_{\mathrm{i}}$, is evaluated from the Nusselt correlation (Holman, 1997)

$h_{\mathrm{i}}=1.13\left(\frac{g r_{\text {steam }} \rho_{\text {water }}\left(\rho_{\text {water }}-\rho_{\text {steam }}\right) \lambda_{\text {water }}{ }^{3}}{\mu_{\text {water }}\left(t_{\mathrm{s}}-t_{\mathrm{w}}\right) H}\right)^{1 / 4}$

In Eq.(6), $\eta_{\mathrm{o}}$ is the finned surface efficiency, which may be written in terms of the fin efficiency $\eta$, fin surface area $A_{\mathrm{f}}$ and total surface area $A_{\mathrm{o}}$, as follows

$\eta_{\mathrm{o}}=1-\frac{A_{\mathrm{f}}}{A_{\mathrm{o}}}(1-\eta)$ 
where $A_{\mathrm{o}}=A_{\mathrm{f}}+A_{\mathrm{b}}, A_{\mathrm{f}}$ and $A_{\mathrm{b}}$ are the areas of the fin and base surface, respectively. $\eta$ is calculated by the approximation method described by Schmidt (Schmidt, 1949).

The thermal and hydraulic performance of the heat exchanger is presented in the following dimensionless forms

$$
\begin{aligned}
& R e=\rho u_{\max } D_{\mathrm{c}} / \mu \\
& N u=h_{\mathrm{o}} D_{\mathrm{c}} / \lambda \\
& j=N u /\left(\operatorname{RePr}^{1 / 3}\right) \\
& f=\frac{2 \Delta p}{\rho u_{\text {max }}^{2}} \frac{D_{\mathrm{c}}}{F_{\mathrm{L}}}
\end{aligned}
$$

where $u_{\max }$ is the velocity at the minimum free flow area, $u_{\max }=u_{\mathrm{fr}} / \sigma$. The term $\sigma$ is the ratio of the minimum flow area to frontal area.

\subsection{Thermal and Hydraulic Performance}

The thermal and hydraulic performance of the finned flat-tube heat exchanger with single row is shown in Figures 3 and 4, where the air frontal velocity and Reynolds number in the heat exchanger is taken as the abscissa in Figure 3 and Figure 4, respectively.

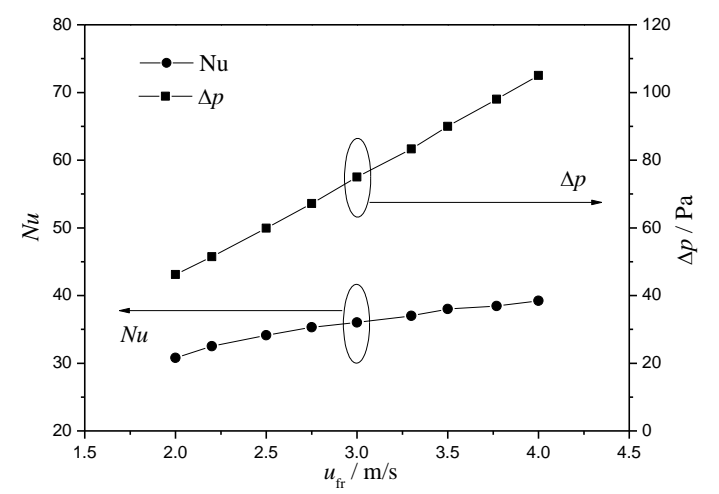

Fig. 3 Thermal and hydraulic performance versus air frontal velocity.

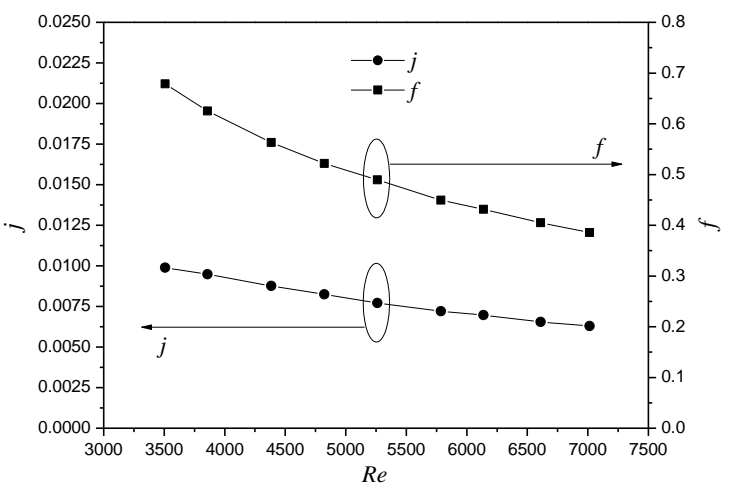

Fig. 4 Thermal and hydraulic performance versus Reynolds number.

In Figure 3, it can be seen that the thermal performance increases with the increase of air frontal velocity. As is well known, increasing the speed of the condenser fan can increase the air frontal velocity, thus, the heat transfer rate of the condenser is increased so as to reduce the back pressure of the turbine at high temperatures in summer. But it is worth to point out that with the increase of air frontal velocity, the increasing rate of Nusselt number decreases. It can also be seen from Figure 3 that the pressure drop increases with the increase of air frontal velocity, because with the increase of air velocity, the turbulence intensity of the air flow in air-side increases, resulting in the increase of pressure drop. In a sense, these results can be expected, because the enhancement of heat transfer is usually penalized by the increase of pressure drop. In Figure 4, it can be seen that the $j$-factor and $f$-factor decrease with the increase of Reynolds number.

The correlations for $j$-factor and $f$-factor can be expressed as

$$
j=c_{1} R e_{\mathrm{D}_{\mathrm{c}}}{ }^{{ }^{2}} \quad f=c_{3} R e_{\mathrm{D}_{\mathrm{c}}}{ }^{{ }^{c_{4}}}
$$

Based on the experimental data, the correlations of $j$-factor and $f$ factor are given as follows

$$
j=2.14 R e_{\mathrm{D}_{\mathrm{c}}}^{-0.657} \quad f=501.4 R e_{\mathrm{D}_{\mathrm{c}}}^{-0.81}
$$

In above correlations, the range of Reynolds number is from 3000 to 7500 . These correlations can be referred to engineering applications or further researches such as optimization or prediction.

\section{NUMERICAL RESULTS AND DISCUSSION}

\subsection{Physical and Mathematic Model}

Due to the geometrical symmetry of the flow domain, only one-half of the heat exchanger element has been computed, as shown in Figure 5.

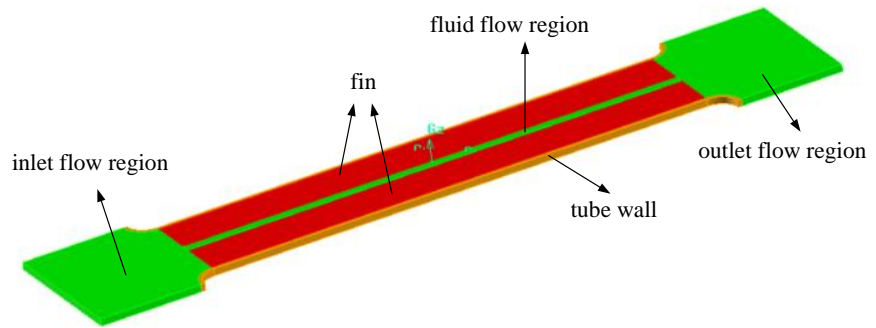

Fig. 5 Schematic diagram of the physical model.

The dimensionless equations for continuity, momentum and energy may be expressed in tensor rotation as (Versteeg et al., 2007)

$\nabla \cdot(\rho \vec{V} \phi)=\nabla \cdot\left(\Gamma_{\phi} \operatorname{grad} \phi\right)+S_{\phi}$

In the above equation, the dependent variable, $\phi$, stands for the velocity components, temperature, $k$ and $\varepsilon, \Gamma_{\phi}$ and $S_{\phi}$ represent the appropriate diffusion coefficients and the source terms, respectively.

Because the governing equations are elliptic in spatial coordinates, boundary conditions are required for all boundaries of the computational domain. At the inlet boundary, the flow velocity $u_{\text {in }}$ is assumed to be uniform, and the temperature $t_{\text {in }}$ is set as $298 \mathrm{~K}$. At the downstream end of the computational domain, streamwise gradients (Neumann boundary conditions) of all the variables are set as zero. On the solid surfaces (flat tube, fin), no-slip conditions are used and a uniform tube inside-wall temperature $t_{\mathrm{w}}$ are specified as $373 \mathrm{~K}$, and the temperature distribution in the tube outside-wall will be determined by solving the conjugated heat transfer problem between air and flat tube in the computational domain.

ANSYS Fluent 14.0 is used for the numerical solution of the Navier-Stokes and energy equations. A preprocessor Gambit 2.4 is used to mesh the computational domain for the solver. Fluent uses a controlvolume-based technique to convert the governing equations to algebraic equations that can be solved numerically. This procedure involves subdividing the region in which the flow is to be solved into individual cells or control volumes so that the equations can be integrated numerically on a cell-by-cell basis to produce discrete algebraic (finite volume) equations. The air flow is assumed to be incompressible ideal gas, turbulent, quasi-steady, 3-D and exhibiting no viscous dissipation. All variables, including velocity components, pressure and temperature, are averaged for a control volume. The coupling between pressure and velocity is implemented by the SIMPLEC algorithm. The QUICK scheme is used for the spacial discretization of the momentum, turbulent kinetic energy, turbulent dissipation rate and energy equations in the simulations. The standard $k-\varepsilon$ turbulence model with wall functions is adopted. The residuals are less than $10^{-5}$ and $10^{-8}$ for the continuity and energy equations, respectively, to ensure convergence of the computations.

\subsection{Grid Independence and Code Validation}

In order to validate the solution independency of the grid number, four different grid systems are investigated. They are about 250,000, 375,000 , 500,000, and 625,000. The predicted averaged Nusselt 
numbers for the four grid systems are shown in Figure 6. The average Nusselt number and $f$-factor differences between 375,000 and 500,000 spaced meshes are both less than $1.0 \%$. The relative differences of average Nusselt number and $f$-factor between 500,000 and 375,000 spaced mesh are also both less than $1.0 \%$. Hence, the 500,000 mesh element number is selected as a reference mesh size.

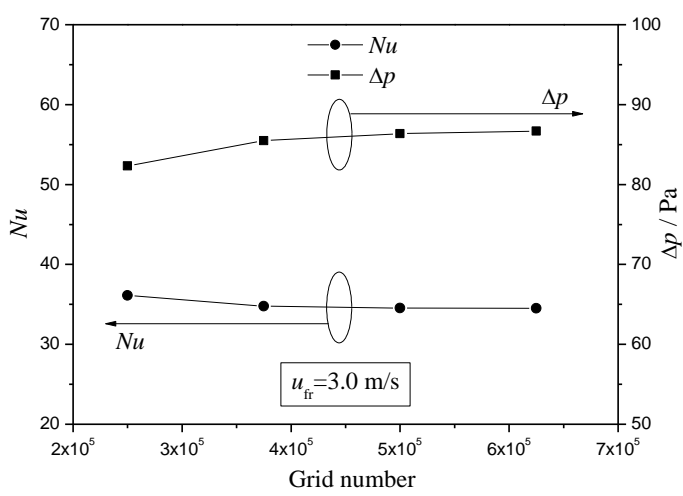

Fig. 6 Variation of grid independence.

In order to validate the reliability of numerical simulation procedure, numerical simulations are carried out at the same operating conditions as in the experiments, and comparison with the experimental results. Figure 7 shows the comparisons between the simulation results and the experimental results. Compared to the experimental results, the maximum and average relative deviations of the Nusselt number are $5.4 \%$ and $4.3 \%$, respectively, and the maximum and average relative deviations of the $f$-factor are $4.0 \%$ and $3.5 \%$, respectively, which show the reliability of the present physical model and numerical method.

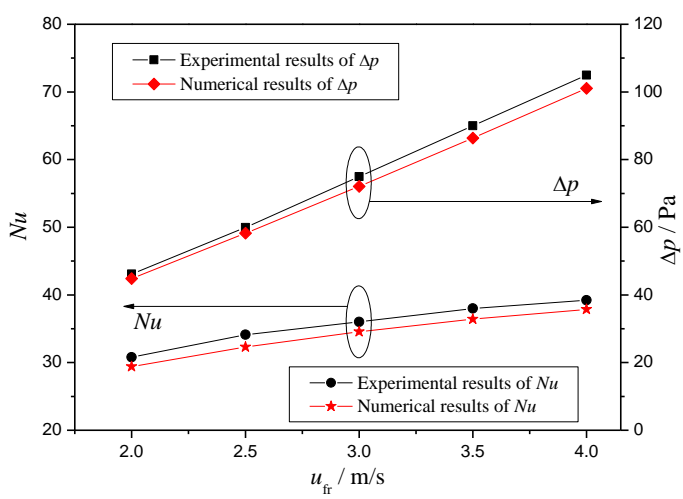

Fig. $7 N u$ and $\Delta p$ comparisons.

\subsection{Effects of Various Geometrical Parameters}

The effect of the fin pitch on the thermal and hydraulic of the finned flat-tube heat exchanger with single row at $u_{\mathrm{fr}}=3.0 \mathrm{~m} / \mathrm{s}$ is shown in Figure 8.

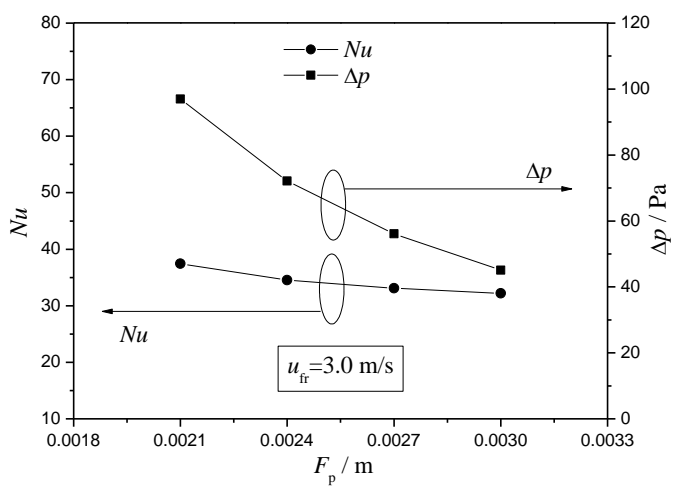

Fig. 8 Effect of fin pitch on the thermal and hydraulic performance.
The effect of the fin length on the thermal and hydraulic of the heat exchanger at $u_{\mathrm{fr}}=3.0 \mathrm{~m} / \mathrm{s}$ is shown in Figure 9 . It can be seen from Figure 9 that with the increase of fin length, both Nusselt number and pressure drop increase, while the decreasing rate of pressure drop is larger than that of Nusselt number. Based on the numerical data, the Nusselt number and the pressure drop are increased by $30.2 \%$ and $60.1 \%$, respectively, as the fin length increases from $0.175 \mathrm{~m}$ to $0.25 \mathrm{~m}$. But it should be pointed out that the Nusselt number almost remains a constant when the fin length is greater than $0.2 \mathrm{~m}$.

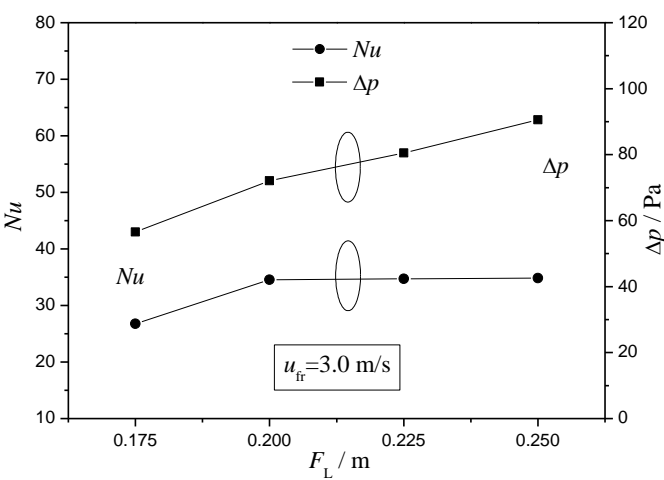

Fig. 9 Effect of fin length on the thermal and hydraulic performance.

Figure 10 shows the effect of the fin height on the thermal and hydraulic of the heat exchanger at $u_{\mathrm{fr}}=3.0 \mathrm{~m} / \mathrm{s}$. In Figure 10 , it can be seen that with the increase of fin height, both Nusselt number and pressure drop increase, and the decreasing rate of pressure drop is larger than that of Nusselt number. Based on the numerical data, the Nusselt number and the pressure drop are increased by $2.2 \%$ and $30.3 \%$, respectively, as the fin height increases from $0.016 \mathrm{~m}$ to $0.019 \mathrm{~m}$.

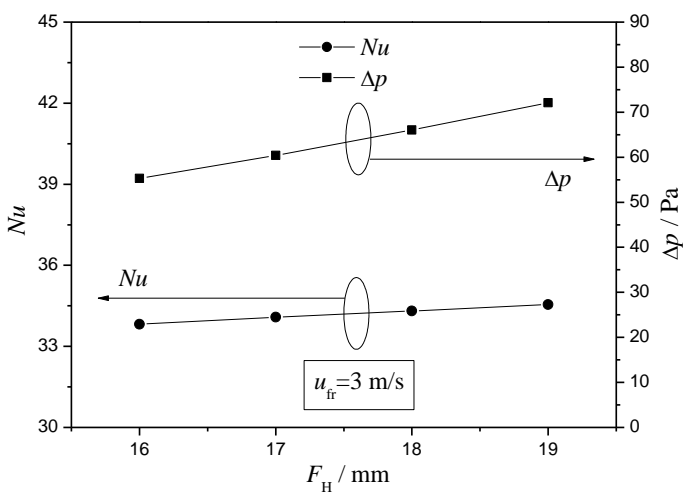

Fig. 10 Effect of fin height on the thermal and hydraulic performance.

\section{OPTIMIZATION BY THE TAGUCHI METHOD}

In general, the thermal and hydraulic performance is used to describe the performance of a heat exchanger. The research results show that the pressure drop will increase as the heat transfer is increased. So for the heat exchanger design, it is difficult to simultaneously increase heat transfer and reduce pressure drop. However, the design goal of a new heat exchanger is efficient heat transfer and low pressure drop. Therefore, a new parameter is defined to evaluate the heat transfer and pressure drop using the Taguchi method. The thermal and hydraulic of heat exchangers are presented by $j$ and $f$ factors, respectively. In the present study, the $J F$ factor, related to the $j$ and $f$ factors, is evaluated as the thermal and hydraulic performance for these cases. The $J F$ factor is a dimensionless number of the larger-the-better characteristics, and is defined as follows (Tang et al., 2019b).

$J F=\frac{j / j_{\text {ref }}}{\left(f / f_{\text {ref }}\right)^{1 / 3}}$ 
where $j_{\text {ref }}$ and $f_{\text {ref }}$ are the $j$ and $f$ factors of the original heat exchanger.

The control factors used in this study are made up of three factors, i.e., fin pitch, fin length and fin height, related to the heat transfer surface area and the turbulence in the air-side. The levels of each factor in this study are shown in Table 2. These factors are selected based on the above numerical database. In this study, $R e_{\mathrm{Dc}}$ is taken as the signal factor and the noise factor is not considered.

Table 2 Levels of each factor.

\begin{tabular}{|l|l|l|l|l|l|l|}
\hline Code & $\begin{array}{l}\text { Factors } \\
\text { (unit) }\end{array}$ & $\begin{array}{l}\text { Level } \\
1\end{array}$ & $\begin{array}{l}\text { Level } \\
2\end{array}$ & $\begin{array}{l}\text { Level } \\
3\end{array}$ & $\begin{array}{l}\text { Level } \\
4\end{array}$ & $\begin{array}{l}\text { Level } \\
5\end{array}$ \\
\hline A & Fin pitch/m & 0.0024 & 0.0027 & 0003 & 0.0033 & 0.0036 \\
\hline B & Fin length/m & 0.15 & 0.175 & 0.2 & 0.225 & 0.25 \\
\hline C & Fin height $/ \mathrm{m}$ & 0.016 & 0.017 & 0.018 & 0.019 & 0.02 \\
\hline
\end{tabular}

The $S N$ (signal-to-noise) ratio usually is used in quality engineering and experimental design, which is invented by Taguchi. $S N$ ratio can help engineers to find out which levels of control factors are more efficient. In present study, the $S N$ ratio of the dynamic characteristics is defined as the following equation

$S N=-10 \lg \left(\frac{1}{N} \sum_{i=1}^{N} \frac{1}{J F_{\mathrm{i}}^{2}}\right)$

An orthogonal array of $L_{25}\left(3^{5}\right)$ is established based on the numerical database in this study as shown in Table 3.

Table 3 The orthogonal array of $L_{25}\left(3^{5}\right)$ and $S N$ ratio.

\begin{tabular}{|c|c|c|c|c|}
\hline Number of test & $\mathrm{A}$ & B & $\mathrm{C}$ & $S N$ \\
\hline 1 & 1 & 1 & 1 & -0.039 \\
\hline 2 & 1 & 2 & 3 & -0.187 \\
\hline 3 & 1 & 3 & 5 & -0.351 \\
\hline 4 & 1 & 4 & 2 & -0.259 \\
\hline 5 & 1 & 5 & 4 & -0.288 \\
\hline 6 & 2 & 1 & 5 & -0.193 \\
\hline 7 & 2 & 2 & 2 & -0.025 \\
\hline 8 & 2 & 3 & 4 & -0.08 \\
\hline 9 & 2 & 4 & 1 & -0.069 \\
\hline 10 & 2 & 5 & 3 & -0.073 \\
\hline 11 & 3 & 1 & 4 & -0.053 \\
\hline 12 & 3 & 2 & 1 & 0.135 \\
\hline 13 & 3 & 3 & 3 & 0.057 \\
\hline 14 & 3 & 4 & 5 & -0.114 \\
\hline 15 & 3 & 5 & 2 & 0.201 \\
\hline 16 & 4 & 1 & 3 & 0.076 \\
\hline 17 & 4 & 2 & 5 & -0.091 \\
\hline 18 & 4 & 3 & 2 & 0.222 \\
\hline 19 & 4 & 4 & 4 & 0.095 \\
\hline 20 & 4 & 5 & 1 & 0.135 \\
\hline 21 & 5 & 1 & 2 & 0.158 \\
\hline 22 & 5 & 2 & 4 & 0.096 \\
\hline 23 & 5 & 3 & 1 & 0.119 \\
\hline 24 & 5 & 4 & 3 & 0.143 \\
\hline 25 & 5 & 5 & 5 & -0.196 \\
\hline
\end{tabular}

Factorial effect and contribution ratio of every factor are presented in Table 4 and Figure 11, respectively. The $S N$ ratio of each factor in Table 4 is derived from the arithmetic average of $S N$ ratios corresponding to each level in Table 3 . The $R$ is the difference of maximum and minimum of the $S N$ ratio for every factor. The contribution ratio is equal to the value of the $R$ number of each factor dividing the total $R$ of all factors. The contribution ratio stands for the influence of every factor on the $J F$ factor, which is the symbol of the thermal and hydraulic performance of a heat exchanger. In Table 4 and
Figure 11, it can be seen that the fin pitch has the largest influence on the $J F$ factor, and the last one is the fin length.

Table 4 Factorial effect and contribution ratio.

\begin{tabular}{|l|l|l|l|l|}
\hline & Level & $\mathrm{A}$ & $\mathrm{B}$ & $\mathrm{C}$ \\
\hline \multirow{5}{*}{$S N$ ratio } & 1 & -0.2248 & -0.0102 & 0.0562 \\
\cline { 2 - 5 } & 2 & -0.0880 & -0.0144 & 0.0594 \\
\cline { 2 - 5 } & 3 & 0.0452 & -0.0066 & 0.0032 \\
\cline { 2 - 5 } & 4 & 0.0874 & -0.0408 & -0.0460 \\
\cline { 2 - 5 } & 5 & 0.0640 & -0.0442 & -0.1890 \\
\hline$R$ (Max-Min) & 0.5982 & 0.3122 & 0.0376 & 0.2484 \\
\hline Contribution ratio & 1.0 & 0.522 & 0.063 & 0.415 \\
\hline
\end{tabular}

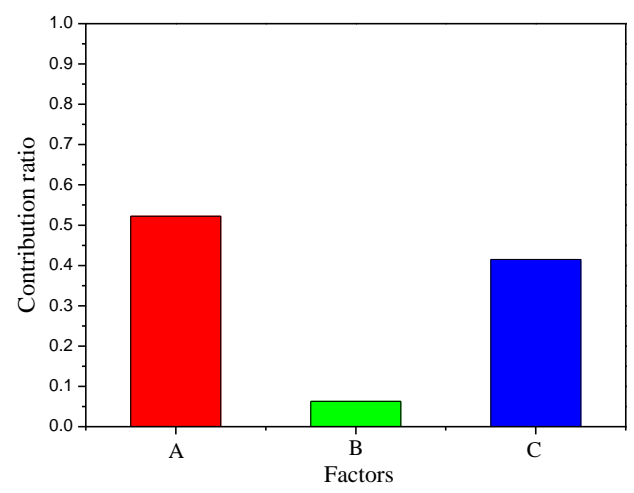

Fig. 11 Contribution ratio of each factor.

Figure 12 shows the $S N$ ratio of each factor to be considered in selecting the optimal condition. This means that the largest $S N$ ratio level of all the levels on each factor has the best performance as mentioned above. As shown in Figure 12, Level $4(0.0033 \mathrm{~m})$ is the best for the fin pitch. Selecting a suited fin pitch is necessary in optimal design process of a heat exchanger. A small fin pitch means more fins per unit and also means more heat transfer area, but the pressure drop problem will arise at the same time. As far as the fin length is concerned, $0.2 \mathrm{~m}$ is the best. The reason is that with the increase of fin length, Nusselt number and pressure drop both increase, but the decreasing rate of pressure drop is larger than that of Nusselt number when the fin length is greater than $0.2 \mathrm{~m}$. The fin length at the central indicates the optimal condition at the $0.017 \mathrm{~m}$ level. This is because both Nusselt number and pressure drop increase with the increase of fin height, but the increasing degree of pressure drop is larger than that of Nusselt number.

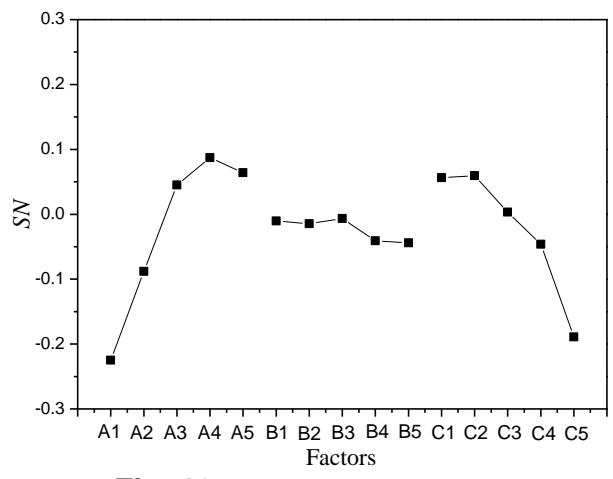

Fig. $12 S N$ ratio of each factor.

The optimal condition is A4B3C2 obtained by the Taguchi method. Figure 13 compares the $J F$ factor of the optimal configuration and the original heat exchanger versus the Reynolds number. The $J F$ factor of the optimal condition is considerably higher than that of the original 
heat exchanger. It is thus demonstrated that the optimal condition performs better than the original heat exchanger.

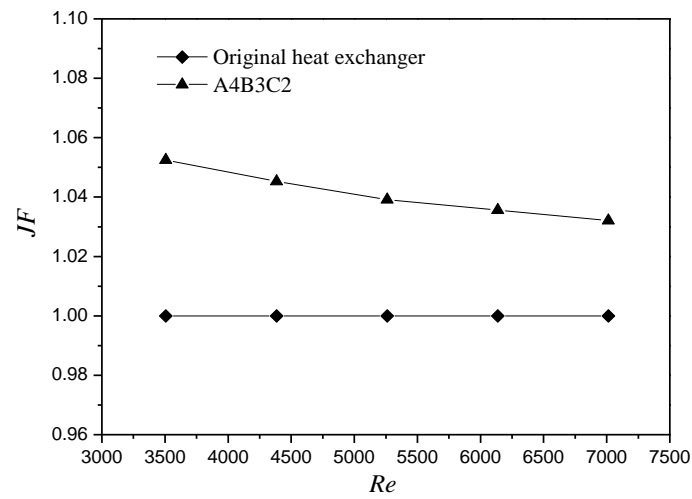

Fig. $13 \mathrm{JF}$ factor comparisons of optimal condition and original heat exchanger

\section{CONCLUSIONS}

The thermal and hydraulic performance of the finned flat-tube heat exchanger with single row is experimentally and numerically investigated in this study. The main conclusions can be summarized as follows:

(1) The Nusselt number and pressure drop increase with the increase of air frontal velocity. Based on the experimental results, the heat transfer and friction factor correlations for the heat exchanger are acquired with Reynolds numbers ranging from 3000 to 7500 .

(2) The effects of fin pitch, fin length and fin height on the thermal and hydraulic performance of the heat exchanger are analyzed by a numerical method. The results indicate that with the increase of fin pitch, the heat transfer and pressure drop decrease, and with the increase of fin length and height, the heat transfer and pressure drop increase.

(3) The optimal conditions of each factor are determined, and the optimal condition is A4B3C2 obtained by the Taguchi method.

\section{ACKNOWLEDGEMENTS}

This work is supported by the Natural Science Basic Research Plan in Shaanxi Province of China (No. 2020JM-539).

\section{NOMENCLATURE}

A area, $\mathrm{m}^{2}$

$A_{\mathrm{b}} \quad$ area of the base surface, $\mathrm{m}^{2}$

$A_{\mathrm{c}} \quad$ minimum flow area, $\mathrm{m}^{2}$

$A_{\mathrm{f}} \quad$ area of the fin surface, $\mathrm{m}^{2}$

$A_{\text {fr }} \quad$ frontal area, $\mathrm{m}^{2}$

$A_{\mathrm{i}} \quad$ heat transfer area of water side, $\mathrm{m}^{2}$

$A_{0} \quad$ total surface area of air-side, $\mathrm{m}^{2}$

$c_{1}, c_{2}, c_{3}, c_{4}$ coefficient of formulation

$c_{\mathrm{p}} \quad$ specific heat at constant pressure, $\mathrm{J} /(\mathrm{kg} \mathrm{K})$

$D_{\mathrm{c}} \quad$ fin collar outside diameter, $D_{\mathrm{c}}=D_{\mathrm{o}}+2 \delta_{\mathrm{t}}, \mathrm{m}$

$F_{\mathrm{H}} \quad$ fin height, $\mathrm{m}$

$F_{\mathrm{L}} \quad$ fin length, $\mathrm{m}$

$F_{\mathrm{p}} \quad$ fin pitch, $\mathrm{m}$

$f \quad$ Darcy friction factor

$g \quad$ gravity acceleration, $\mathrm{m} / \mathrm{s}^{2}$

$h_{\mathrm{i}} \quad$ heat transfer coefficient of water side, $\mathrm{W} /\left(\mathrm{m}^{2} \cdot \mathrm{K}\right)$

$h_{\mathrm{o}} \quad$ heat transfer coefficient of air-side, $\mathrm{W} /\left(\mathrm{m}^{2} \cdot \mathrm{K}\right)$

$J F \quad J F$ factor

$j \quad$ Colburn factor

$k \quad$ overall heat transfer coefficient, $\mathrm{W} /\left(\mathrm{m}^{2} \cdot \mathrm{K}\right)$

$L \quad$ length of front area

$m$ mass flow rate, $\mathrm{kg} / \mathrm{s}$

$\begin{array}{ll}\mathrm{Nu} & \text { Nusselt number } \\ \mathrm{Pr} & \text { Prandtl number } \\ Q & \text { heat transfer rate, } \mathrm{W} \\ r & \text { latent heat of vaporization, } \mathrm{J} / \mathrm{kg} \\ \operatorname{Re} & \text { Reynolds number } \\ \mathrm{S} & \text { flat tube pitch, } \mathrm{m} \\ t & \text { temperature, } \mathrm{K} \\ u, v, w & x, y, z \text { velocity components, } \mathrm{m} / \mathrm{s} \\ W & \text { width of front area, } \mathrm{m} \\ x, y, z & \text { Cartesian co-ordinates }\end{array}$

Greek Symbols

$\Delta p \quad$ pressure drop, $\mathrm{Pa}$

$\Delta t_{\mathrm{m}} \quad$ logarithmic mean temperature difference, $\mathrm{K}$

$\delta \quad$ thickness, $\mathrm{m}$

$\eta \quad$ fin efficiency

$\eta_{\mathrm{o}} \quad$ surface efficiency

$\lambda$ thermal conductivity, $\mathrm{W} /(\mathrm{m} \cdot \mathrm{K})$

$\mu \quad$ dynamic viscosity of fluid, $\mathrm{kg} /(\mathrm{m} \cdot \mathrm{s})$

$\rho \quad$ density, $\mathrm{kg} / \mathrm{m}^{3}$

$\sigma \quad$ contraction ratio of the fin array

$\begin{array}{ll}\text { Subscripts } & \\ \text { air } & \text { air } \\ \text { ave } & \text { average } \\ \mathrm{f} & \text { fin } \\ \mathrm{fr} & \text { frontal area } \\ \mathrm{i} & \text { inside } \\ \text { in } & \text { inlet } \\ \text { max } & \text { maximum value } \\ \text { out } & \text { outlet } \\ \text { ref } & \text { reference value } \\ \mathrm{s} & \text { saturated steam } \\ \text { steam } & \text { steam } \\ \mathrm{t} & \text { flat tube } \\ \text { water } & \text { water }\end{array}$

\section{REFERENCES}

Dezan, D.J., Salviano, L.O., and Yanagihara, J.I., 2015, "Interaction Effects between Parameters in a Flat-Tube Louvered Fin Compact Heat Exchanger with Delta-Winglets Vortex Generators," Applied Thermal Engineering, 91, 1092-1105. http://dx.doi.org/10.1016/j.applthermaleng.2015.08.072

Duan, F., Song, K.W., Li, H.R., Chang, L.M., Zhang, Y.H., and Wang, L.B., 2016, "Numerical Study of Laminar Flow and Heat Transfer Characteristics in the Fin Side of the Intermittent Wavy Finned Flat Tube Heat Exchanger," Applied Thermal Engineering, 103, 112-127. http://dx.doi.org/10.1016/j.applthermaleng.2016.04.081

Erbay, L.B., Uğurlubilek, N., Altun, Ö., and Doğan, B., 2017, "Numerical Investigation of the Air-Side Thermal Hydraulic Performance of a Louvered-Fin and Flat-Tube Heat Exchanger at Low Reynolds Numbers," Heat Transfer Engineering, 38(6), 627-640. http://dx.doi.org/10.1080/01457632.2016.1200382

Holman, J. P., 1997, Heat Transfer, $8^{\text {th }}$ ed., McGraw-Hill.

Karthik, P., Kumaresan, V., and Velraj, R., 2015a, "Fanning Friction (f) and Colburn (j) Factors of a Louvered Fin and Flat Tube Compact Heat Exchanger," Thermal Science, 21(1A), 141-150. https://doi.org/10.2298/TSCI131118088K

Karthik, P., Kumaresan, V., and Velraj, R., 2015b, "Experimental and Parametric Studies of a Louvered Fin and Flat Tube Compact Heat Exchanger using Computational Fluid Dynamics", Alexandria Engineering Journal, 54, 905-915. http://dx.doi.org/10.1016/j.aej.2015.08.003 
Ozturk, M.M., Doğan, B., and Erbay, L.B., 2019, "Performance Analysis of a Compact Heat Exchanger with Offset Strip Fin by Nonuniform Uninterrupted Fin Length," Applied Thermal Engineering, 159, 113814.

https://doi.org/10.1016/j.applthermaleng.2019.113814

Roy, R.K., 2010, A Primer on the Taguchi Method, $2^{\text {nd }}$ ed., Society of Manufacturing Engineers.

Schmidt, T.E., 1949, "Heat Transfer Calculations for Extended Surfaces," Refrigerating Engineering, 57, 351-357.

Sahel, D., Ameur, H., and Kamla, Y., 2017, "A Numerical Study of Fluid Flow and Heat Transfer over a Fin and Flat Tube Heat Exchangers with Complex Vortex Generators," European Physical Journal Applied Physics, 78(3), 34825.

http://dx.doi.org/10.1051/epjap/2017170066

Sadeghianjahromi, A., Kheradmand, S., Nemati, H., Liaw, J.S., and Wang, C.C., 2018, "Compound Heat Transfer Enhancement of Wavy Fin-and-Tube Heat Exchangers through Boundary Layer Restarting and Swirled Flow," Energies, 11(8), 1959. http://dx.doi.org/10.3390/en11081959

Taweny, R., Khan, Z., and Zachary, J., 2005, "Economic and Performance Evaluation of Heat Sink Options in Combined Cycle Applications," Journal of Engineering for Gas Turbines and Power, 127(2), 891-898.

http://dx.doi.org/10.1115/1.1839924

Tang, L.H., Tan, S.C., Gao, P.Z., and Zeng, M., 2016, "Parameters Optimization of Fin-and-Tube Heat Exchanger with a Novel Vortex Generator Fin by Taguchi Method," Heat Transfer Engineering, 37(34), 369-381.

http://dx.doi.org/10.1080/01457632.2015.1052715
Tang, L.H., Pan, J., and Sundén, B., 2019a, "Parametric Study and Optimization on Heat Transfer and Flow Characteristics in a Rectangular Channel with Longitudinal Vortex Generators," Numerical Heat Transfer, Part A: Applications, 76(11), 830-850. http://dx.doi.org/10.1080/10407782.2019.1673095

Tang, L.H., Du, X.P., Pan, J., and Sundén, B., 2019b, “Air Inlet Angle Influence on the Air-Side Heat Transfer and Flow Friction Characteristics of a Finned Oval Tube Heat Exchanger," International Journal of Heat and Mass Transfer, 145, 118702. https://doi.org/10.1016/j.ijheatmasstransfer.2019.118702

Versteeg, H.K., and Malalasekera, W., 2007, An Introduction to Computational Fluid Dynamics: the Finite Volume Method, Pearson Education.

Wang, Q.W., Zhang, D.J., Zeng, M., Lin, M., and Tang, L.H., 2008, "CFD Simulation on a Thermal Power Plant with Air-Cooled Heat Exchanger System in North China," Engineering Computations, 25(4), 342-365. http://dx.doi.org/10.1108/02644400810874958

Xu, C., Yang, L., Li, L., and Du, X., 2015, "Experimental Study on Heat Transfer Performance Improvement of Wavy Finned Flat Tube," Applied Thermal Engineering, 85, 80-88. http://dx.doi.org/10.1016/j.applthermaleng.2015.02.024

Yang, L., Du, X., Yang, Y., and Liu, D., 2007, "Monitoring of Dust Accumulation on Direct Air-cooled Steam Condensers in Thermal Power Plants," Journal of Engineering for Thermal Energy and Power, 22(2), 172-175. (In Chinese)

Zeng, M., Tang, L.H., Lin, M., and Wang, Q.W., 2010, "Optimization of Heat Exchangers with Vortex-Generator Fin by Taguchi Method," Applied Thermal Engineering, 30(13), 1775-1783. http://dx.doi.org/10.1016/j.applthermaleng.2010.04.009 